\title{
Promoção da memória social a partir de documentos arquivísticos em centros de memória do Poder Judiciário Federal brasileiro: em foco a memória, o patrimônio e a informação
}

\author{
Rodrigo Costa Japiassu
}

Promoção da memória social a partir de documentos arquivísticos em centros de memória do Poder Judiciário Federal brasileiro: em foco a memória, o patrimônio e a informação Resumo: Apontam-se alguns fundamentos teóricos para o desenvolvimento do trabalho de promoção da memória social com documentos arquivísticos. Considerando-se a memória como uma construção social e processual, relaciona-se memória e arquivo para a problematização de caminhos para o trabalho desnaturalizado destes documentos, perpassados pelas perspectivas do patrimônio e da informação. Verifica-se como a história dos arquivos e a escrita contribuíram para a formação dos lugares da memória de Pierre Nora, bem como o surgimento de diversos sentidos sobre memória. Articulou-se patrimônio à memória, tentando-se obter, a partir da discussão acerca dos valores patrimoniais, elementos para se pensar os processos de patrimonialização de documentos arquivísticos e a construção desnaturalizada da memória social e da informação sobre estes documentos.

Palavras-chave: Documento arquivístico. Memória. Memória social. Patrimônio. Informação

Promoting social memory from archival documents in memory centers of the Brazilian Federal Judiciary: focusing memory, heritage and information

Abstract: They point out some theoretical foundations for the development of the promotion work of social memory with archival documents. Considering the memory as a social and procedural construction, relates to memory and file for questioning paths for denatured work of these documents, perpassados the prospects of the assets and information. It can be seen as the history of files and writing contributed to the formation of the places of Pierre Nora's memory as well as the emergence of differently on memory. Articulated is worth the memory, trying to get from the discussion of asset values, elements to think about the heritage processes of archival documents and the denatured construction of social memory and information about these documents.

Key Words: Archival document. Memory. Social Memory. Heritage. Information 


\section{Introdução}

A discussão acerca do que é memorável ganha espaço cada vez maior na contemporaneidade. Aparentemente como um sintoma de que a memória não é mais vivida internamente, ou como resposta a situações de distensões sociais e políticas ${ }^{1}$, surgem espaços de discussão que reivindicam a (re)criação de memórias - muitas vezes subterrâneas (POLLAK, 1989) - como uma construção processual (GONDAR, 2005).

Nesse panorama, surgem trabalhos de (re)construção da memória pela sociedade civil e, também, pelo Estado. Sejam na forma de projetos memória ou memoriais/centros de memória, parecem indicar uma certa necessidade de se instituírem lugares de memória (NORA, 1993), como os arquivos. Registre-se, contudo, que a própria existência destes lugares pode ser vista como um sintoma da construção da Modernidade, de aceleração do tempo, de crescente industrialização e de valorização do individualismo nas sociedades modernas. Afinal, "fala-se tanto de memória porque ela não existe mais" (NORA, 1993, p. 7).

Se os lugares de memória são criados, é porque está sempre presente uma complementaridade/oposição entre memória e esquecimento que não pode ser desprezada (LE GOFF, 1996, p. 422; POLLAK, 1989; HUYSSEN, 2014). O caráter seletivo da memória tem o poder de (re)produzir falas autorizadas, que pretendem ser representantes legítimas de determinada instituição. Contudo, até que ponto representam amplamente tal instituição? Como essas memórias - em muitos casos, na verdade, memórias-prótese (NORA, 1993) -conseguem dialogar de forma construtiva com a sociedade? Este processo de produção de memórias - na verdade, em forma de vestígios (POMIAN, 2000), materializada em documentos -, com pretensões de patrimonialização, deve ser atentamente observado.

Quando se tem em perspectiva a relação entre arquivo e memória, outros elementos importantes surgem: uma escrita especializada, burocrática, sua relação íntima com o poder e a importância da História, a partir da Modernidade (NORA, 1993; LE GOFF, 1996; ROUSSEAU; COUTURE, 1998; SILVA, 2002; ASSMANN, 2011). Observe-se que o arquivo não é neutro nem "imparcial" e que há disputas sobre o que é dizível em sua escrita, remetendo-se à noção foucaultiana de arquivo. De fato, "controle do arquivo é controle da memória" (ASSMANN, 2011, p. 368), e o que fica registrado tem o poder de determinar o que pretende-se ser memorável.

Verifica-se na atualidade uma verdadeira febre de memória, em que várias instituições esforçam-se em criar eventos que divulguem suas memórias institucionais, bem como uma multiplicidade de memórias sociais. O campo informacional entendido aqui como Arquivologia, Biblioteconomia, Museologia e Ciência da Informação - também encontra-se incluído nesse processo, o que se evidencia pela criação recente de eventos em que a temática da memória possui importância central.

${ }^{1}$ Como, por exemplo, as movimentações que deram origem à criação da Comissão Nacional da Verdade no Brasil.

${ }^{2}$ Ao contrário do que defende boa parte da literatura arquivística quando da definição das características de um documento arquivístico, em especial quando explicitam seu funcionamento em âmbito administrativo. 
Por exemplo, no âmbito do Poder Judiciário Federal brasileiro ${ }^{3}$, recentemente surgem eventos como os Seminários Nacionais de Museus e Centros de Memória do Poder Judiciário, que caminha para a sua $3^{a}$ edição ou, ainda, a criação da Rede de Memória da Justiça Eleitoral, em 2014.

De qual memória se fala, inclusive considerando-se o direito à memória como um mecanismo de promoção da cidadania? Como os documentos arquivísticos - aqui entendidos como documentos produzidos por pessoa jurídica, entidade coletiva, pessoa ou família no cumprimento de suas atividades, independente de forma ou suporte contribuem para a promoção de memórias junto à sociedade? Problematizar a relação entre arquivo e memória (social), considerando-se também as questões referentes ao patrimônio e à informação, permite obter melhores subsídios acerca dos (des)caminhos por onde se constrói o trabalho memorial nos centros de memória do Poder Judiciário Federal brasileiro.

\section{A memória social a partir dos documentos arquivísticos}

Em trabalho - com foco arquivístico - que verificou a produção científica da memória no campo informacional brasileiro, Oliveira (2010) observou que a relação entre memória e informação realiza-se predominantemente sob o viés da memória social. Neste trabalho, a memória social foi especificada como uma categoria onde "predomina a vinculação do conceito [de memória] à informação registrada, bem como à sua organização e preservação", mencionando-se, ainda, questões quanto à "construção da identidade de grupos sociais" e à caracterização de "arquivos, bibliotecas e museus como instituições de memória” (OLIVEIRA, 2010, p. 80).

Ao se verificarem os trabalhos que relacionavam memória à informação na categoria memória social na tese de Oliveira (2010), podem-se destacar, pela sua pertinência, os seguintes temas como representativos do trabalho de promoção da memória sobre documentos arquivísticos: identidade (cultural), legitimidade, gestão de passados sensíveis, direito à informação/à memória, produção de conhecimento, lembrança, esquecimento, patrimônio cultural, lugares de memória e ação cultural. Ressalte-se que há uma forte relação original entre arquivo e memória que deve ser considerada na elaboração de tal trabalho (NORA, 1993; LE GOFF, 1996; ASSMANN, 2011).

A partir destes temas, devem-se levantar elementos para a possível construção de políticas públicas de memória. Observe-se que os temas supracitados reforçam o caráter social - e, não raro, também público - da informação (FROHMANN, 2008). Tal caráter assemelha-se à concepção da memória como uma construção social e processual (GONDAR, 2005), visto que a informação, assim como a memória, é influenciada pela linguagem e pela cultura.

Surge aqui o sujeito, como "construtor e construído, [...] perpassado por concepções de mundo que o constituem e de interesses existentes no ambiente em que vive" (FERNANDES, 2006, p. 24). Importa ressaltar apenas a diferença de temporalidade em relação à construção da memória e da informação a partir de

${ }^{3}$ Conforme a Constituição Federal de 1988, os ramos que compõem o Poder Judiciário Federal brasileiro são as Justiças Eleitoral, Federal, Trabalhista, Militar, bem como os Tribunais Superiores, Conselho da Justiça Federal e Conselho Nacional de Justiça. 
documentos, sendo a primeira feita geralmente a priori e a segunda, a posteriori em relação à produção destes.

Observou-se que a criação dos centros de memória dos tribunais que compõem o Poder Judiciário Federal é fenômeno recente, ocorrendo em especial a partir do início deste século. Será válido considerar esta explosão memorial como um sintoma da perda dos meios de memória, como afirma Nora (1993), em especial nos grandes centros urbanos? Ou, ainda, como um possível ressurgimento da monumentalização dos espaços que, em tese, garantiriam a estabilidade do tempo e espaço face à aceleração do tempo, típica da contemporaneidade (HUYSSEN, 2000)?

No que tange aos documentos arquivísticos, em geral, trabalha-se com processos judiciais (e administrativos, com menos frequência), documentos fundantes destes tribunais (ata de criação, pauta de julgamento de processos, certidão de julgamento, etc.), acórdãos, livros de ata, ementários produzidos pelos próprios tribunais que constituíram tais centros e boletins de apuração de eleições como os tipos documentais mais comuns nesses centros. Destes, os processos judiciais possuem destaque absoluto.

A princípío, a aparente utilização predominante dos documentos arquivísticos desses centros de memória no sentido de "documento-monumento" (LE GOFF, 1996) é preocupante, já que tende a não favorecer trabalhos construtivos de ação cultural com a sociedade. Com base em Milanesi (2003), pode-se entender a ação cultural no campo informacional como um conjunto de iniciativas que têm como objetivo criar condições para o cidadão se inserir na sua realidade de forma consciente, através de ações dialógicas e criativas realizadas a partir de acervos documentais de forma desnaturalizada e se torne sujeito da cultura e não, seu objeto. A produção de memórias sociais a partir da intermediação de profissionais da informação (e das Ciências Humanas e Sociais como um todo) entre tais acervos e a sociedade é uma das possibilidades vislumbradas para tais trabalhos de ação cultural.

Construir a memória (inclusive em suas vertentes, tais como social, institucional, etc.) pressupõe um indivíduo concebido como sujeito de suas próprias ações. Ademais, tal processo construtivo pressupõe quatro elementos, de acordo com Pollak (1992): eventos, personagens, lugares de memória e vestígios (SANTOS, 2013, p. 135).

Trabalhar a memória nessa perspectiva mais reflexiva exclui a possibilidade de vê-la como algo coisificado, imutável ou, ainda, que funcione basicamente como elemento de coesão social (HALBWACHS, 2006). O que interessa observar aqui é exatamente o que a singulariza, as condições de sua produção e a possibilidade de sua promoção em âmbito social contribuir para a formação de cidadãos críticos $\mathrm{e}$ conscientes na sociedade. Dos elementos anteriormente citados, destaquem-se os lugares de memória e os vestígios como os mais representativos para a discussão acerca da relação entre o documento arquivístico e a memória social.

Para chegarmos aos vestígios, aqui caracterizados como documentos (arquivísticos), primeiramente será articulada uma relação entre memória e arquivo. Diversos autores (LE GOFF, 1996; HALBWACHS, 2006; NORA, 1993) consideram que a transmissão dos saberes nas sociedades sem escrita se dava através da memória. Tal transmissão fundava-se basicamente no compartilhamento contínuo de experiências de caráter prático através das gerações em um espaço com ligação afetiva entre seus membros, que se tornavam tradições com a continuidade destas transmissões no tempo. 
Essa memória - associável aos mitos de origem de determinados grupos (LE GOFF, 1996, p. 424) - dependia dos meios de memória (NORA, 1993) para sua perpetuação. A esses grupos que reproduziam esses saberes práticos no tempo, Nora (1993) denominou-os como sociedades de memória. Somente com a "arte da memória" (YATES, 2007) é que se vislumbra uma primeira noção de memória que a aproxima da escrita, quando do uso, por indivíduos, da mnemotécnica a partir de imagens - por vezes, inscritas em suportes como cavernas e tábuas de cera - para memorização. Contudo, neste caso, trata-se de uma memória artificialmente criada a partir do funcionamento da mente, não vivenciada socialmente.

Le Goff (1996) aponta - inclusive com o auxílio de outros autores, como LeroiGourhan - um discutível caráter evolucionista na criação ${ }^{4}$ da escrita, como um desenvolvimento "natural" das sociedades, que é sempre considerada como um excesso da memória. Aponta que um dos efeitos desta criação é o surgimento do documento, caracterizado como um "monumento" (LE GOFF, 1996, p. 428), digno de registrar tudo aquilo que deve ser memorável às futuras gerações.

Concordamos com Freitas (2012), que apresenta um contraponto à essa criação naturalizada da escrita, considerando tal criação como resultante de disputas sociais, em que o letramento torna-se fator de estratificação social. À diferença do funcionamento coesivo da memória (HALBWACHS, 2006) nas sociedades de memória, parece-nos realmente que a criação da escrita e sua materialização nos documentos (inclusive os arquivísticos) e os locais de guarda destes ajuda a apontar diferenças sensíveis entre memória e arquivo.

\section{Uma breve história dos arquivos: do distanciamento da memória à criação dos lugares de memória}

A história do surgimento dos arquivos encontra-se associada à criação da escrita (ROUSSEAU; COUTURE, 1998). Embora sem um consenso, aponta para suas origens a Antiguidade, em torno de 3 a 4 milênios a.C., na antiga Mesopotâmia (atual Iraque). Já a essa época, aponta-se um caráter elitista da escrita, quando são criados arquivos "a serviço das classes dirigentes" (SILVA, 2002, p. 46), armazenados em locais de difícil acesso, tais como santuários.

Chama a atenção de que, durante toda a Idade Antiga e, também, durante a Idade Média, na Europa e no atual Oriente Médio, tanto os arquivos (como instituições arquivísticas) quanto os documentos arquivísticos tenham originalmente surgido e se desenvolvido como representantes de uma escrita do Estado. Uma forte característica destes documentos é serem criados como "uma necessidade para o exercício do poder" (ROUSSEAU; COUTURE, 1998, p. 32).

Há outros aspectos relevantes que indicam um distanciamento destes documentos do sentido de uma "memória viva", tal como apregoada por Nora (1993). Em geral, apontam para o tratamento especializado dos documentos por funcionários dos reinos onde se encontravam armazenados, bem como o entendimento de tais

\footnotetext{
${ }^{4}$ Ainda que Pomian (2000, p. 510) entenda tratar-se da invenção da escrita, prefere-se adotar o termo criação, pois entende-se que o uso deste termo valoriza o caráter de produção de símbolos que podem ser comunicados a/compartilhados com outras pessoas e grupos, mais próximo do conceito antropológico de cultura.
} 
documentos como propriedade real. Aqui, evidenciam-se estreitas relações com o poder instituído (VIVAS MORENO, 2004), não tendo, neste sentido, sofrido grandes alterações até os dias atuais. Ademais, o sentido de memória aplicado era, na verdade, uma memória-prótese (NORA, 1993), posto que deveria servir de apoio às atividades administrativas. No máximo, poderia ser caracterizado como uma espécie de mnemotécnica (YATES, 2007) para o desenvolvimento de tais atividades:

Desde a mais Alta Antiguidade que o homem sentiu a necessidade de conservar a sua própria 'memória', primeiro sob forma oral, depois sob a forma de grafitti e de desenhos e, finalmente, graças a um sistema codificado, isto é, com símbolos gráficos correspondentes a sílabas ou a letras. A memória [...] constituiu e constitui ainda a base de toda e qualquer actividade humana: a existência de um grupo social seria impossível sem o registo da memória, ou seja, sem arquivos. (LODOLINI, 1989, p. 157 apud ROUSSEAU; COUTURE, 1998, p. 34 , grifos no texto original)

Outro ponto que chama a atenção é a arquitetura dos locais de guarda dos documentos arquivísticos. Sempre imponentes - palácios, igrejas e castelos são alguns exemplos -, sua monumentalidade impressiona. Choay (2011) aponta que o sentido original da palavra monumento, como um artefato intencionalmente construído, guarda uma significação memorial, relacionada à identidade de grupos sociais. Contudo, esta autora adverte que, com o desenvolvimento da imprensa e das obras impressas - como os livros - na Idade Média, o sentido de "monumento" move-se na direção "do caráter imponente ou grandioso associado ao adjetivo "monumental"” (CHOAY, 2011, p. 13). Tal caráter parece mais apropriado para caracterizar tais locais, haja vista $o$ funcionamento exposto dos arquivos e dos documentos arquivísticos aparentemente distanciar-se do caráter dinâmico e afetivo da memória.

Somente a partir da Idade Moderna, com a Revolução Francesa é que se começa a observar maior proximidade entre a memória (mas, também, a História) e o arquivo. Contudo, também é o momento de surgimento da História como disciplina científica, que desafiará a existência das sociedades de memória.

É a partir da Revolução Francesa que se criam instituições arquivísticas abertas ao público para custodiarem os documentos-monumentos (LE GOFF, 1996) surgidos através da História-Memória (NORA, 1993), ou seja, uma História com função histórico-memorial. Tal função pode ser compreendida como aquela em que os arquivos são mobilizados predominantemente para fins de promoção/invenção de uma memória nacional ou institucional ${ }^{5}$, naturalizando-se e reificando-se agentes políticos e objetos que sejam considerados dignos de serem "monumentalizados". Nessa perspectiva, também podem-se considerar documentos (inclusive os arquivísticos) como monumentos, de acordo com a construção realizada por Le Goff (1996).

A criação de tais instituições objetivava a uma maior democratização ao acesso aos arquivos, tentando-se mesmo um processo de apagamento dos registros da ordem política então vigente, no intuito de se promover uma pretensa "memória nacional".

\footnotetext{
5 A memória institucional é considerada aqui como uma memória que reconstitui fatos, narrativas e acontecimentos selecionados como representativos da trajetória de uma instituição no tempo, referida a rituais que contribuem para a construção de sua identidade institucional e de sua legitimidade entre seus membros e, também, junto à sociedade em geral.
} 
Aqui, fica evidente o caráter seletivo da memória, posto que a formação dessa memória reificada é realizada através de processos seletivos dos símbolos nacionais. Contudo, tem-se aqui uma memória cristalizada, padronizada, diferente de um sentido dinâmico, múltiplo, com significados diversos, construída em um grupo social, concepções mais trabalhadas quanto à noção de memória social (GONDAR, 2005).

É o momento de criação dos Arquivos Nacionais. Sua concepção original de "guardiões" da memória nacional - ou melhor, de uma memória do Estado, monolítica e padronizada - leva à concepção dos arquivos como lugares de memória (NORA, 1993). Tais lugares são símbolos da aceleração do tempo característica da Modernidade, sintomas de um tempo onde começa a se perceber mais intensamente a ausência da memória "viva".

O sentido de memória nesses lugares é nostálgico, como recuperação de lembranças de tempos que não mais podem ser resgatados, revividos, eis que perdidos os meios de memória, tais como igrejas, praças e festas populares. Assim são esses arquivos públicos criados na Modernidade: jogando com a memória e o esquecimento, ajudam a criar um projeto de Nação, no qual os documentos arquivísticos são uma expressão bastante visível, ajudando a desenvolver uma memória manipulada (HUYSSEN, 2014), ou mesmo enquadrada (POLLAK, 1989).

No Brasil, muitos arquivos públicos intentam ser reconhecidos como lugares de memória. Aqui, destaque-se a criação do Arquivo Nacional, em 1838. Sintoma do triunfo do binômio documento-História e da institucionalização da memória nacional, originou-se na esteira de um projeto positivista de escrita para a História, na intenção desta se instituir como ciência (COSTA, 2000). Posteriormente, com a criação da História como disciplina científica, será consolidada uma memória arquivística, caracterizada como "a constituição gigantesca e vertiginosa do estoque material daquilo que nos é impossível lembrar" (NORA, 1993, p. 15).

O sentido da memória "encontrada" nos documentos arquivísticos a partir de então é o de memória-prótese. Memória não mais espontânea, mas transformada em vestígios - materializados em documentos (inclusive arquivísticos) - de uma era onde não se fala mais das origens de um povo, mas do nascimento de uma sociedade. Memória atualizadora e ritualística, História crítica e científica: eis o tempo vivido da memória e o tempo fraturado da História.

Oliveira (2010, p. 160) alerta que o "documento institucional", ou seja, o documento arquivístico geralmente é produzido com uma intencionalidade. Sua "monumentalização" é um processo normalmente construído de forma calculada, de modo a fazer lembrar às gerações posteriores de fatos e personagens registrados como dignos de serem memoráveis. Os meios e agentes de seleção dos "documentosmonumentos" são fatores importantes para a compreensão do contexto de formação dos acervos documentais dos centros de memória.

Quais memórias pretendem-se ser reproduzidas para a sociedade? Que outras tantas memórias podem estar sendo silenciadas pela ausência/falta de interesse na busca de um trabalho mais construtivo com a sociedade da promoção de memórias de determinada instituição a partir de determinados documentos? $\mathrm{O}$ próprio processo seletivo desses documentos deve ser amplo e, dentro do possível, buscar a colaboração de setores da sociedade, no intuito de ser desenvolver um trabalho de promoção e mesmo reelaboração da memória social mais efetivo. 
Tal viés mais democrático no trabalho com essa documentação torna-se ainda mais importante na atualidade no Brasil. Mecanismos de acesso à informação ${ }^{6}$ têm sido desenvolvidos como reflexos de uma participação mais articulada de setores da sociedade brasileira, reclamando por uma maior transparência no acesso a documentos outrora inacessíveis à sociedade.

A restrição de acesso a estes documentos é um aspecto que ilustra bem os mecanismos de enquadramento de memórias (POLLAK, 1989) no processo de produção destes. Observe-se que tal enquadramento pode apontar para ausências cuidadosamente trabalhadas para induzir à produção de determinados sentidos a partir de tais documentos. Nesse trabalho, o objetivo é expor uma visão seletiva e parcial acerca de atividades, agentes e, em última instância, da própria instituição mantenedora desses documentos.

Considerando-se a história dos arquivos e sua ligação direta com o poder e as questões envolvendo, inicialmente, controle de acesso a documentos e a monumentalidade dos edifícios, observa-se a todo tempo o caráter dos documentos arquivísticos considerados como patrimônio. Inicialmente, este patrimônio é de caráter estatal e, posteriormente, de caráter público, sempre articulando-se com a memória, como se verá a seguir.

\section{O entendimento sobre o patrimônio e a discussão dos seus valores}

Trabalhar com patrimônio, mais do que se referir apenas à materialidade de objetos a serem selecionados - que também podem se referir a documentos -, implica em uma construção acerca dos valores percebidos sobre tais objetos.

O conceito moderno de patrimônio é inicialmente concebido sob os valores histórico e artístico. Em uma perspectiva monumentalizada, elitista e pretensamente universalista, bens privados eram selecionados pela suposta capacidade de "simbolizar ou de representar metaforicamente a ideia abstrata de nação [...]" (ABREU, 2015, sem paginação).

O processo de patrimonialização associado a estes valores fundava-se na visão da História como reconstrução objetiva do passado e subsidiária da ideia de Estadonação (ABREU, 2009), bem como a formação do que poderia se entender como arte nacional (ABREU, 2015). Não raro, este processo poderia estar associado também à noção de monumento histórico, mais voltado à construção de um saber histórico do que propriamente com intenções memoriais (CHOAY, 2011). Normalmente, referem-se a patrimônios referendados pelo Estado, no intuito de se definir o que é considerado como símbolo nacional.

A partir da criação do conceito antropológico de cultura, "que privilegia os processos sociais pelos quais os homens significam e interpretam o mundo e a si mesmos" (SOUZA; CRIPPA, 2011, p. 246), o conceito de patrimônio é ressignificado. Considera-se a criação deste conceito como fundante de um segundo momento dos processos de patrimonialização (ABREU, 2015).

Nessa nova perspectiva, valores como os sociais e culturais passam a se sobressair, expondo uma visão que tende a ser mais democrática sobre o que deve ser

${ }^{6}$ Tome-se como exemplo a Lei de Acesso à Informação, bem como o funcionamento das ouvidorias em diversos órgãos públicos e privados. 
considerado como patrimônio, bem como a emergência de outros agentes sociais que participam desse caráter seletivo. Ou seja, aqui o foco é na atribuição de uma significação simbólica - e não na materialidade - que o objeto pode assumir para culturas locais/regionais. Abreu (2009) mostra uma reflexão importante, que ajuda a sinalizar a emergência de novos agentes participantes no processo de patrimonialização também da cultura popular, e não somente da cultura erudita: "ao formular a ideia de diversidade cultural, é preciso levar em conta o substrato que a ancora: as culturas são diversas como expressões da igualdade entre os homens" (ABREU, 2009, p. 47-48).

Pode-se dizer que a noção de patrimônio na contemporaneidade tende a dar menor força a um caráter de excepcionalidade ou, ainda, a um discurso relacionado à perda de um certo passado monumental. Nestas situações, percebe-se um viés elitista que tenderia a reproduzir personagens tidos como históricos e construções que refletissem um sentido de memória nacional (NORA, 1993).

Contudo, a influência dos estudos antropológicos sobre o patrimônio faz com que este passe a ser mais valorizado como um processo. A partir daí, são cada vez mais consideradas as manifestações relacionadas à cultura popular: normalmente ritualizadas, com transmissão geracional em um grupo e vínculo afetivo e onde o caráter de ensinamento das experiências compartilhadas coletivamente é valorizado, baseado na narratividade (BENJAMIN, 2012; GAGNEBIN, 2013). Ou seja, apontam-se características que valorizam a coesão social através da memória (HALBWACHS, 2006). Contudo, muito além desse caráter coesivo da memória, deve-se observar o processo de patrimonialização de objetos, bem como os agentes participantes deste processo para melhor caracterização da formação de um patrimônio.

Pensar o documento arquivístico como um patrimônio aponta para a observação dos valores anteriormente citados. Estas questões ganham um tom memorial ao se considerar tais documentos preservados em lugares de memória públicos, como os centros de memória de tribunais do Poder Judiciário Federal, já que envolve a formação de memórias oficiais (POLLAK, 1989). Em última instância, ajudam a formar a própria noção de identidade nacional.

Pensar nos valores histórico e, eventualmente, artístico destes documentos implica em observá-los na direção dos "documentos-monumentos". O caráter de memória oficial - na direção de uma memória da dominação (ASSMANN, 2011) - que pode-se tentar construir sobre esses documentos pode silenciar memórias subterrâneas, que não se referem somente aos grupos dominados (POLLAK, 1989), mas que também podem estar omitidos em documentos - arquivísticos, inclusive.

Este silêncio - geralmente proposital - de se omitirem, por exemplo, pensamentos e atos desfavoráveis de determinado grupo dirigente, favorece, ou melhor, tende a manipular a futura criação de uma memória institucional favorável. Em uma perspectiva discursiva, observa-se a formação de políticas do silêncio (ORLANDI, 2007), em que estas remetem a processos de apagamento e censura sobre sujeitos. Aponta-se o poder, materializado na linguagem - e, neste caso, registrado em documentos arquivísticos -, de seleção do que pode ser dito (e do que deve ficar oculto) e do que é proibido dizer. Tais escolhas sempre refletem o caráter ético e político da memória social (GONDAR, 2005), como projeto atualizado de construção de memórias no tempo e no espaço. 
A consideração dos valores sociais e culturais dos documentos arquivísticos já permitiria, em tese, perceber tais documentos numa perspectiva mais construtivista. Nessa direção, mais do que sua representação objetiva - considerada como "o referente estático do que se encontra em constante movimento" (GONDAR, 2005, p. 23) -, os símbolos atribuídos permitem atualizar a compreensão sobre estes documentos, como objetos patrimonializáveis a partir dos quais vislumbra-se (re)inserir um saber sobre esses objetos que pode ser (re)atualizado na memória social.

Vislumbra-se aqui uma nova relação entre memória e informação, agora "atravessada" pelo patrimônio. Será retomada a concepção construtivista de informação como produção de sentido de matiz sociocultural. Neste viés, tem-se que os objetos patrimonializados podem ser trabalhados de forma participativa com os cidadãos que interagem com tais objetos. Estes cidadãos podem ser vistos como sujeitos, a partir de Ronald Day. Ao apontar aspectos éticos no trabalho com informação, afirma que não seriam "somente sujeitos 'a governança', mas [também] sujeitos 'para expressão', e devem ser educados e informados nesta última direção", criando sujeitos "desejosos por informação" (DAY, 2015, sem paginação, tradução nossa).

No caso, trata-se de informação construída a partir do saber produzido sobre o objeto patrimonializado, e não uma "informação-como-coisa" (BUCKLAND, 1991), positivada. Também não é uma informação no sentido de notícia jornalística, que "aspira a uma verificabilidade imediata" (BENJAMIN, 2012, p. 219), associável a um esquema passivo emissor-receptor, sem qualquer produção de sentido quanto à informação, que remete à Teoria Matemática da Comunicação, de Shannon e Weaver.

Neste processo, pode-se (re)construir uma memória social a partir deste objeto construído como patrimônio. Não se trata aqui da perda da "aura", da dessacralização do objeto, vista inclusive por Benjamin (2012) como positiva, em que o autor considera que a perda da experiência e da autenticidade desse objeto permitiria, na verdade, uma ressignificação desse objeto em outros espaços. Ressalte-se que os espaços também podem ser simbólicos e/ou políticos, referidos a lugares e posições sociais de onde se originam os sujeitos potencialmente produtores de memórias a partir de tais objetos.

Memória atualizada e realimentada pelas perspectivas projetadas sobre os objetos patrimonializados: eis o caráter performático do patrimônio. Afinal, no que se denomina como uma abordagem comunicacional da patrimonialização, tem-se que "uma das funções principais do saber é reconstruir, reconstituir a memória perdida do objeto e de seu mundo de origem, de seu contexto de produção, isto é, a transmissão memorial que está ausente" (DAVALLON, 2015, sem paginação). Importa ressaltar que, caso tal saber seja documentado junto com o patrimônio, o processo de patrimonialização necessita de revisões periódicas. Esta atividade torna-se necessária para evitar um certo engessamento da memória, que tornar-se-ia algo próximo a uma mnemotécnica para compreensão desse patrimônio.

Pode-se considerar a existência de documentos arquivísticos em centros de memória como uma possibilidade da formação de um patrimônio arquivístico. Seu conceito é fornecido pelo Dicionário de Terminologia Arquivística do Arquivo Nacional como o "conjunto de arquivos de valor permanente, públicos ou privados, existentes no âmbito de uma nação, estado ou município" (ARQUIVO NACIONAL, 2005, p. 130). O valor permanente é uma noção arquivística, considerada como sinônimo de valor secundário. Este é considerado o valor que um documento arquivístico possui para ser 
mantido permanentemente para fins probatórios (legais) das atividades desenvolvidas por uma instituição e/ou para fins de pesquisa.

Ademais, o valor permanente também é conhecido como valor histórico até os dias atuais. Esta menção a um suposto "caráter histórico" do documento arquivístico também encontra-se referenciada na própria definição de arquivo presente na Lei de Arquivos (Lei $n^{\circ}$ 8.159/91). Provavelmente, reflete ainda a importância dada ao caráter originalmente "monumental" dos arquivos brasileiros. Estes, a partir da Modernidade, possuem o Estado como um local destacado de sua produção, verdadeiros "lugares de história" na acepção de Le Goff (1996). São lugares assim concebidos, posto que formam parte dos "criadores e denominadores da memória coletiva" (LE GOFF, 1996, p. 467), aqui referenciados, na verdade, à memória nacional.

Medeiros (2011) reconhece que o início da construção de um patrimônio arquivístico no Brasil é contemporâneo ao processo de monumentalização dos arquivos verificado no período pós-Revolução Francesa. $\mathrm{O}$ entendimento acerca desse patrimônio "começou com a ideia de uma escrita de história para o país ainda no século XIX" (MEDEIROS, 2011, p. 36), ocorrida graças à atuação do Instituto Histórico e Geográfico Brasileiro, criado em 1838 - que, como já visto, foi o mesmo ano da criação do Arquivo Nacional, originalmente concebido como "guardião" da memória nacional brasileira.

A percepção da atuação da função histórico-memorial junto aos arquivos brasileiros passa, também, pelo reconhecimento legal do que seja considerado patrimônio histórico. Nessa situação, pode-se verificar o Decreto-Lei no 25, de 1937, o qual, por influência da criação do Serviço do Patrimônio Histórico e Cultural (SPHAN, atualmente IPHAN), "organiza a proteção do patrimônio histórico [e que], mesmo não citando a palavra arquivo, engloba e coloca em evidência a ligação de bens que sejam relevantes para a história do Brasil" (MEDEIROS, 2011, p. 36).

A atual Constituição Federal brasileira acompanhou as influências antropológicas que ampliam a concepção de patrimônio e dos novos agentes sociais surgidos nesse processo. Foi influenciada pela atuação da UNESCO, de organizações não-governamentais e mesmo de instâncias governamentais - como o Conselho Federal de Cultura (CFC) e o Instituto Nacional de Referência Cultural (INRC) - que, ainda que com um viés mercadológico e homogeneizador, fomentaram o reconhecimento de diversas manifestações culturais de caráter memorial como. Passou a reconhecer manifestações típicas da cultura popular, mesmo que continue a referendar o valor histórico de um patrimônio.

Influenciada pela ampliação do que se considerava como patrimônio, a partir das influências do conceito antropológico de cultura em sua redefinição - em que houve a inclusão nessa categoria, por exemplo, de documentos, festas e religiões populares, através de eventos como a criação da antiga Fundação Nacional Pró-Memória (GONÇALVES, 1988) -, confere significação cultural ao patrimônio brasileiro (cf. MEDEIROS, 2011, p. 37), em que os documentos são incluídos como parte do patrimônio cultural brasileiro, em seu Art. 216, IV.

Contudo, deve-se refletir que mesmo o reconhecimento constitucional dessa concepção ampliada de patrimônio não garante por si só a elaboração de políticas de patrimônio e de memória. A legislação é parte integrante de uma política, mas não é a própria política. Outras questões, como os valores patrimoniais, os agentes sociais 
envolvidos e as formas de trabalho sobre patrimônio e memória são da maior importância e devem ser consideradas para a adequada elaboração destas políticas.

\section{Considerações finais}

Buscou-se aqui construir caminhos para uma construção desnaturalizada de memórias (sociais) a partir de documentos arquivísticos em centros de memória do Poder Judiciário Federal. Nesse trajeto, vislumbrou-se sempre uma conexão com a memória social como uma construção social e processual - saída do tempo mitológico e inserida no tempo humano - e que vai muito além de sua representação (GONDAR, 2005), bem como com a abordagem historicista da Ciência da Informação. Esta abordagem é concebida como "uma teoria que enfatiza que a percepção e o pensamento são sempre influenciados por nossa linguagem, cultura, [e] através de nossa précompreensão e 'horizontes' [na construção da informação] [...]" (HJORLAND, 1998, p. 608, tradução nossa).

Acredita-se que tal abordagem guarda bastante pertinência com o trabalho de construção de memórias supracitado, já que considera um sujeito reflexivo, que imprime suas percepções particulares. Nesta perspectiva, tem o poder de influenciar na compreensão de tal documento, (re)interpretando-o à luz de suas visões de mundo sociais, culturais e históricas.

Não se pode perder de vista a questão dos valores de um patrimônio para o trabalho envolvendo promoção de memórias. $\mathrm{O}$ maior peso dado a determinados valores tende a apontar indícios por onde se pretende trabalhar a memória, e pode ajudar, também, no trabalho de construção de informação a partir de documentos arquivísticos, aqui vistos como objetos patrimonializados. O projeto de memória a ser trabalhado implica em perspectivas de presente e de futuro sobre a ação cultural com estes documentos, inclusive pela questão da informatividade destes, que é sempre "elaborada por práticas e discursos, de forma circunstancial e temporal, o que sempre a relativiza" (SOUZA; CRIPPA, 2011, p. 247).

Deve-se trabalhar a perspectiva de uma interlocução mais articulada e inclusiva com a sociedade no trabalho de ação cultural com documentos arquivísticos em centros de memória. Por sinal, um entendimento mais reflexivo do que se entende por memória a partir destes documentos - como uma construção social e processual e não, como um dado arqueologizável - pode ajudar a trazer novos elementos para se pensar a promoção da memória de forma desnaturalizada, fazendo com que não se relacione apenas às memórias nacional e institucional - normalmente autorreferidas e naturalizadas -, mas também à memória social.

\section{Referências}

ABREU, Regina. A emergência do patrimônio genético e a nova configuração do campo do patrimônio. In: Memória e patrimônio: ensaios contemporâneos. 2 ed. Rio de Janeiro: Lamparina, 2009.

ABREU, Regina. A patrimonialização das diferenças e os novos sujeitos de direito coletivo no Brasil. In: TARDY, C.; DODEBEI, V. (Orgs.) Memória e novos patrimônios. Marseille: Open Edition Press, 2015. 
ARQUIVO NACIONAL (BRASIL). Dicionário brasileiro de terminologia arquivística. Rio de Janeiro: Arquivo Nacional, 2005.

ASSMANN, Aleida. Espaços da recordação. Formas e transformações da memória cultural. Campinas: Ed. Unicamp, 2011.

BENJAMIN, Walter. Magia e técnica, arte e política: ensaios sobre a literatura e história da cultura. 8. ed. São Paulo: Brasiliense, 2012.

BUCKLAND, Michael. Information as thing. Journal of the American Society of Information Science and Technology, v. 42, n. 5, p. 351-360, 1991.

CHOAY, Françoise. Introdução. In: . O patrimônio em questão: antologia para um combate. Belo Horizonte: Fino Traço, 2011.

COSTA, Célia Maria Leite. O Arquivo Público do Império: o legado absolutista na construção da nacionalidade. Estudos Históricos, Rio de Janeiro, v. 14, n. 26, 2000, p. 217-231.

DAVALLON, Jean. Memória e patrimônio: por uma abordagem dos regimes de patrimonialização. In: TARDY, C.; DODEBEI, V. (Orgs.) Memória e novos patrimônios. Marseille: Open Edition Press, 2015.

DAY, Ronald. Information ethics: normative and critical perspectives. Palestra apresentada no Instituto Brasileiro de Informação em Ciência e Tecnologia. Rio de Janeiro, mar/2015. Recebido através do e-mail<ci2015@googlegroups.com>. Acesso em: 22 mar. 2015.

FERNANDES, Geni Chaves. Quatro visões no campo da Ciência da Informação. Rio de Janeiro, 2006. 42 p. Trabalho apresentado à banca avaliadora do concurso para Professor Adjunto $1 \mathrm{DE}$, do Departamento de Ciência da Informação da Universidade Federal de Santa Catarina, como requisito parcial para aprovação. Recebido através do e-mail<ci2015@googlegroups.com>. Acesso em: 10 mar. 2015.

FREITAS, Lídia Silva de. Documento e poder: uma arqueologia da escrita. Morpheus - Revista Eletrônica em Ciências Humanas, Rio de Janeiro, n. 14, p. 58-72, 2012.

FROHMANN, Bernd. O caráter social, material e público da informação. In: FUJITA, Mariângela Spotti Lopes; MARTELETO, Regina Maria; LARA, Marilda Lopes Ginez de (Org.). A dimensão epistemológica da Ciência da Informação e suas interfaces técnicas, políticas e institucionais nos processos de produção, acesso e disseminação da informação. Marília: Fundepe Editora, 2008, p. 19-34.

GAGNEBIN, Jeanne-Marie. Não contar mais? In:

História e narração em

Walter Benjamin. São Paulo: Perspectiva, 2013.

GONDAR, Jô. Quatro proposições sobre memória social. In: GONDAR, Jô; DODEBEI, Vera (Orgs.). O que é memória social? Rio de Janeiro: Contra Capa, 2005. HALBWACHS, Maurice. A memória coletiva. São Paulo: Centauro, 2006.

HJORLAND, Birger. Theory and metatheory in information science: a new interpretation. Journal of Documentation, v. 54, n. 5, p. 606-621, dez. 1998.

HUYSSEN, Andreas. Seduzidos pela memória: arquitetura, monumentos, mídia. Rio de Janeiro: Aeroplano, 2000.

HUYSSEN, Andreas. Culturas do passado-presente. Rio de Janeiro: Contraponto, 2014.

LE GOFF, Jacques. História e memória. 4. ed. Campinas, SP: UNICAMP, 1996. 
MEDEIROS, Enderson. A patrimonialização e o arquivo enquanto patrimônio: um olhar antropológico. Biblos: Revista do Instituto de Ciências Humanas e da Informação, v. 25, n.1, jan./jun. 2011, p.35-45

MILANESI, Luís. A casa da invenção. 4. ed. Cotia, SP: Ateliê Editorial, 2003.

NORA, Pierre. Entre memória e história: a problemática dos lugares. In: Projeto História. São Paulo: PUC, n. 10, p. 07-28, dez./1993.

OLIVEIRA, Eliane Braga de. O conceito de memória na Ciência da Informação: uma análise da produção científica dos programas de pós-graduação. Tese (Doutorado em Ciência da Informação) - Faculdade de Ciência da Informação da Universidade de Brasília, 2010.

ORLANDI, Eni. As formas do silêncio: no movimento dos sentidos. 6. ed. Campinas: UNICAMP, 2007.

POLLAK, Michael. Memória, esquecimento, silêncio. Estudos Históricos, Rio de Janeiro, v. 2, n. 3, 1989, p. 3-15.

POLLAK, Michael. Memória e identidade social. Estudos Históricos, Rio de Janeiro, v. 5 , n. 10,1989 , p. 200-215.

POMIAN, K. Memória. In: GIL, F. Sistemática. Porto: Imprensa Nacional: Casa da Moeda, 2000.

ROUSSEAU, Jean-Yves; COUTURE, Carol. Os fundamentos da disciplina arquivística. Lisboa: Publicações Dom Quixote, 1998.

SANTOS, N. M. W. Memória como narrativas do sensível: entre subjetividades e sensibilidades. In: GRAEBIN, C. M. G.; SANTOS, N. M. W. (Orgs.). Memória Social: questões teóricas e metodológicas. Canoas: UnilaSalle, 2013.

SILVA, Armando Malheiro da et al. Arquivística: teoria e prática de uma ciência da informação. Porto: Edições Afrontamento, 2002. 2. ed.

SOUZA, Willian Eduardo Righini de; CRIPPA, Giulia. O Patrimônio como processo: uma ideia que supera a oposição material-imaterial. Em Questão, Porto Alegre, v. 17, n. 2, p. 237-251, jul./dez. 2011.

VIVAS MORENO, Agustín. El tiempo de la archivística - un estudio de sus espacios de racionalidade histórica. Ci. Inf., Brasília, v. 33, n. 3, p. 76-96, set./dez. 2004.

YATES, Frances A. A arte da memória na Grécia: a memória e a alma. In: A arte da memória. Campinas, SP: Unicamp, 2007. 